\title{
MANUALIZAÇÃO E DISCIPLINARIZAÇÃO DOS SABERES DA LÍNGUA: O CASO DA ENUNCIAÇÁO' ${ }^{1}$
}

Christian Puech ${ }^{2}$

Resumo: $\mathrm{O}$ processo de manualização dos saberes linguísticos concernentes à Enunciação é considerado sob um duplo aspecto: por um lado, as modalidades segundo as quais as teorias da Enunciação, em sua diversidade mesma, emergiram historicamente em uma proximidade problemática com a linguística estrutural: por outro lado, sua integração universitária/escolar progressiva, submetida a outras restriçôes e transplantadas para uma outra história. É na interseção dessas duas "contextualizaçóes" que o "manual" manifesta sua especificidade em relação às "obras eruditas". É em torno da noção complexa de transmissão que se coloca em relação à história das ideias linguísticas, de um lado, e a implementação operatória escolar, de outro. De acordo com quais procedimentos? Com quais efeitos? Mas sobretudo aqui: em que condiçóes?

A “manualização". Este título proposto implica que nos deteremos aqui mais a um processo do que ao produto deste processo. É pelo menos assim que nós o interpretaremos. Trata-se do processo pelo qual os saberes linguísticos se expóem e se difundem com fins operatórios de transmissão, apropriação, reinvestimento, em vez do produto propriamente falando, isto é, do manual como objeto sociocultural claramente identificável pela aproximação/diferenciação (de) com outros produtos socioculturais do mundo erudito: o Tratado, o Ensaio, a Introdução, os Problemas..., termos sobre os quais, nós sabemos, os linguistas contemporâneos intitulam seus trabalhos mais importantes.

Muito esquematicamente, e sem dúvida sem poder desenvolver como

1 Texto originalmente publicado em: PUECH, Christian. " Manuélisation et disciplinarisation des savoirs de la langue ", Les Carnets du Cediscor [En ligne], 5 | 1998, mis en ligne le 15 avril 2009, consulté le 01 octobre 2016. URL: http://cediscor.revues.org/267 Traduçấo de Maria Iraci Sousa Costa, Amanda Eloina Scherer e Maurício Bilião.

2 Professor na universidade Sorbonne Nouvelle Paris-III. Membro do URA 381 « Histoire des théories linguistiques ", trabalha sobre a linguística dos séculos XIX e XX e sobre o processo de disciplinarização das ciências da linguagem (constituição de uma memória disciplinar, partilhas disciplinares, horizonte de projeção da disciplina...). A didatizaçấo é considerada desta perspectiva como um dos aspectos da transmissão e da atestação das teorias linguísticas, de sua consistência disciplinar. Publicou " De l'émergence disciplinaire à la didactisation des savoirs linguistiques : le tournant des années 60 et ses suites " em Langue française $\mathrm{n}^{\circ} 117$ (fevereiro 1998) (em colaboração). 
deveria, eu defenderei o seguinte ponto de vista: a manualização dos saberes linguísticos é um dos aspectos de um processo mais vasto, o processo de disciplinarização dos saberes linguísticos, quer dizer, a constituição desses saberes em "disciplina".

Deste ponto de vista, é claro que a disciplinarização dos saberes linguísticos não começou com a introdução do tema teórico da enunciação, ainda menos com aquela de uma teoria enunciaçáo, sabemos, inatingível no campo muito diversificado das ciências modernas da linguagem. $\mathrm{O}$ domínio da enunciaçáo abrange, com efeito, por todo o mundo uma série de referências, muito amplamente heterogêneas que, de Benveniste a Jakobson e Culioli, de Perelman a Austin e Strawson ou Bakhtin e Weinrich e muitos outros teóricos importantes, desenha uma constelação de "teorias de referência" - eu tomo emprestada aqui deliberadamente uma expressão recorrente da didática - exploradas segundo as necessidades, as ocasiōes, os imperativos didáticos variáveis no campo escolar e segundo o grau de "modernização" das Instruções Oficiais (gramática, gramática textual, estilística...). Com efeito, se não existe no campo dos "saberes eruditos" uma teoria homogênea da enunciaçáo, um sentido unívoco associado ao termo discurso, é muito difícil de discernir no colégio e no liceu um domínio de ensino homogêneo submetido sob esses nomes, mesmo se a noção de "discurso", com a última reforma do colégio, pareça dever estruturar a coerência do ensino de francês. Deste ponto de vista, nós poderíamos dizer que o título desta Jornada consagrada à "manualização das teorias da enunciaçáo" confronta duas heterogeneidades, aquela de um estado contemporâneo das ciências da linguagem, e aquela do mundo escolar concernente ao ensino da língua.

Contudo, a base de referências eruditas todavia identificável não é constituída em uma única vez, a partir de uma fonte única, nem em um único domínio de saber. Ela não tomou forma senão gradualmente, e me parece que ela não pôde entrar de maneira tímida nos manuais, a título de "registro" (para retomar parcialmente o título de uma comunicação anunciada para esta Jornada), senão em uma conjuntura histórica precisa da qual eu pretendo aqui reconstruir, e a título de introdução, alguns parâmetros.

Com efeito, me parece que a manualização das teorias da enunciação pode ser a ocasião para confrontar dois tipos de contextualização de saberes: aquele que preside a constituição dos "saberes eruditos", e aquele que concerne ao mundo escolar, tanto parece evidente que é o ponto preciso 
onde estes dois tipos de contextualização convergem que a manualização dos saberes linguísticos é possível. Em que condiçôes no que concernem as teorias da enunciação? Eu vou me esforçar em nomear estas condiçôes sob a forma de questóes (mais do que de inventariar de maneira exaustiva), e em três momentos:

1. A aparição nos manuais de itens sobre a enunciação supóe, antes de tudo, que os saberes tomam forma, que eles tenham se tornado identificáveis enquanto tais; resumidamente, que eles tenham entrado em um "campo disciplinar". Qual e de que maneira? Quais relaçôes entre a emergência "erudita" e a emergência "escolar" deste campo? Por quais vieses, quais mediaçóes, passa a didatização dos saberes até a sua utilização escolar, quer dizer sua utilização social principal? Qual estatuto os saberes eruditos conferiram ao domínio da enunciação para que o campo enunciativo se tornasse identificável como tal?

2. Na França, o que é implicado, nesta história, é uma certa representação da disciplina, quer dizer, do que nós chamamos hoje as "ciências da linguagem", à época de sua identificação muito forte com o estruturalismo e com os princípios saussurianos; em particular a uma certa interpretação da distinção língua/fala. $\mathrm{O}$ que está nestas condiçôes da introdução de saberes concernente à "conversão da língua em discurso" (cf. Benveniste) neste dispositivo?

3. A defasagem entre a contextualização escolar da enunciação e a constituição do objeto mesmo nos "saberes eruditos". Poderíamos nos contentar com a evidência de que gostaríamos que a enunciação náo tivesse figurando nos programas escolares desde que ela não estivesse concebida nos saberes eruditos? Nós vimos imediatamente que há aqui uma dupla postulação complementar: uma que concerne ao campo escolar concebido como um puro campo de aplicação dos conhecimentos disponíveis, o outro que concerne à natureza mesmo do domínio da enunciação.

\section{Disciplinarizaçáo e manualização}

Se nos determos muito esquematicamente na ideia de que os manuais 
de francês são complexos de representação concernindo ao mesmo tempo: às necessidades dos alunos (o paratexto dos manuais do colégio e do liceu não para de enriquecer); as medidas promovidas na classe em uma certa hierarquia de tarefas (cf. as "atividades principais e secundárias" dos manuais "descompartimentados", os exercícios propostos); a aplicação das Instruções Oficiais (e de seus comentários e textos de acompanhamento), resta que estes diferentes componentes constituem o prisma no qual se reflete uma representação dos saberes disciplinares, da disciplina enquanto "matéria" de ensino (como dizem os alunos) e complexidade de conteúdo.

Embora estes diferentes componentes sejam dificilmente dissociáveis, é a este último aspecto da manualização que eu me interesso aqui prioritariamente, na medida em que me parece que esta representação guia as outras em larga medida, e sobretudo que é ela que coloca em relação o "mundo erudito" e aquele da escola em um duplo dinamismo cujas temporalidades e exigências deslocadas presidem o processo de manualização. Isto se produz, com efeito, no ponto de convergência da disciplina no sentido acadêmico e da disciplina no sentido escolar. A manualização integra então os conteúdos da linguística neste complexo muito heterogêneo que constitui na escola o "francês". Contudo, me parece que por razóes ao mesmo tempo históricas e pedagógicas, o domínio da enunciação é consagrado hoje à conhecer um excessivo investimento em "francês": um fracasso relativo da "linguística aplicada ao ensino" de um lado, de outro lado o rumor social segundo o qual os alunos em fracasso sofreriam antes de tudo de um "déficit de sentidos" assimilados a uma perda de direito - o reconhecimento de um direito universal (?), justificando as últimas versóes dos IO - convergem, com efeito, para uma promoção da enunciação como apropriação última da significação e do mundo cultural em sua totalidade.

Não se trata certamente de pretender que os conteúdos tenham menos importância que sua representação no sentido de uma "disciplina", mas, antes de qualquer coisa, de recolocar em causa uma visão muito confortável da (tâo) famosa "transposição didática". De um lado, nós teríamos os "saberes eruditos", submetido a nenhuma outra restrição senão aquela da verdade, da validação, da finalidade sem fins do interesse desinteressado, e do outro a busca de uma eficácia operatória totalmente subjugada às finalidades exteriores sem outra sanção senão o êxito ou a falha. Em resumo, de um lado o mundo dos produtores, do outro aquele dos usuários.

Contudo, do lado dos inventores do saber, não parece defensável 
pretender que a preocupação com a transmissão não existe, ou que não existiria nenhuma preocupação quanto à contextualização de conhecimentos produzidos. Sem negar a especificidade dos procedimentos de didatização dos saberes, nem aquela do estatuto de seus agentes, me parece que eles não poderiam se configurar se, na origem, um grupo profissional não tivesse assumido a responsabilidade - e tirado os benefícios - da balizagem ao mesmo tempo axiológica, retrospectiva e projetiva de um campo intelectual em via de disciplinarização ${ }^{3}$. É necessário aqui entrar em detalhes, o que nós não poderíamos fazer. $\mathrm{O}$ campo científico da enunciação se constitui em uma relação ao mesmo tempo íntima e com um rompimento em relação ao estruturalismo linguístico, que, como sabemos, acompanhou, guiado ao mesmo tempo por aquilo que alguns tem chamado (para criticar) "o esforço de modernização intelectual" ‘ do pós-guerra, e o esforço de modernização pedagógica nos anos 1960, o qual geralmente se leva menos em conta. Deste ponto de vista, não se deveria considerar que o plano Rouchette constituise como a apoteose escolar do estruturalismo linguístico ${ }^{5}$ que nasceu, fora de toda preocupação com a escola, mas não sem preocupaçáo quanto a transmissão de suas aquisiçóes, nos anos 1920 e 1930? Quanto ao retorno - mas se trata de um retorno? - da enunciação, é mais frequentemente apresentada na perspectiva desta história como a transgressão da distinção língua/fala rigidificada na posteridade de Saussure: a fala não escapa à sistematicidade da língua. Ele acompanha hoje a reflexão pedagógica a partir da preocupaçáo didática de recentramento do ato de ensino sobre o aluno em si mesmo.

O esforço de disciplinarização dos saberes apreendido a partir de discursos de exposição não se limita à simples representação de um domínio pré-existente. Ele organiza também o acúmulo de conhecimentos e de "descobertas" no tempo, agenciando uma trama narrativa. Em seu seio, a herança exposta não é aquela senão a propedêutica à inovação.

Nós nos damos conta, por exemplo, com R. Jakobson, o linguista que, ao longo de uma extensa carreira, exprimiu frequentemente a

3 Cf. esse tema, pouco estudado, as proposiçōes de J. Schlanger que em numerosas obras aceita se colocar do ponto de vista impuro dos inventores-difusores de conhecimentos e de engenharia intelectual, sob muitos aspectos (1983, 1992a, 1992b).

4 Cf. T. Pavel (1988), que não leva em conta em suas denúncias da "miragem linguística" seus efeitos escolares.

5 Cf. para esta tentativa parcial de colocar em perspectiva histórica do período recente e do lugar da enunciação na linguística erudita desta época, C. Normand (1995), O sujeito entre a lingua e a fala(s). 
preocupação de uma representação global da disciplina, ao mesmo tempo em sua especificidade e em sua articulação com outras disciplinas. Em um copioso artigo não publicado em vida e intitulado "A teoria saussuriana em retrospecção" (que os editores póstumos datam de 1942 aproximadamente), Jakobson dialoga com Saussure do CLG e realiza também esse caminho de revisão/filiação dos princípios saussurianos táo significativo da maneira pela qual o estruturalismo sente sua consciência disciplinar a partir de uma memória sempre recolocada em obra:

- Apodera-se da famosa frase do Cours: "Qual é o objeto ao mesmo tempo integral e completo da linguística?"

- Restitui-se o perspectivismo saussuriano: as grandes dicotomias saussurianas concernentes menos ao objeto do que o ponto de vista sobre o objeto;

- Mas a multiplicidade dos pontos de vista sobre a língua não é senão a expressão de um relativismo da época a ultrapassar;

- É necessário então procurar um ponto de vista que importa antes de tudo: aquele da função dada como "ponto de vista primário" presente em Saussure, mas ultrapassando sua perspectiva datada.

A insistência sobre a função de comunicação da linguagem estaria também apresentada implicitamente em Saussure, ela não estaria desprendida explicitamente senão por seu continuador/reformador, que dá, desta maneira, sua significação "verdadeira" na obra fundadora. Tratase no espírito de Jakobson de combater ao lado de Saussure contra o individualismo linguístico para afirmar a dimensão social da linguagem, mas trata-se também de revisar a dicotomia língua/fala para levar em conta "a norma que o indivíduo impóe deliberadamente ou inconscientemente a todas as suas manifestaçôes linguísticas". Resumindo,

\footnotetext{
Nós levamos necessariamente a uma modificação da doutrina saussuriana concernente à língua e à fala. A língua tem, ao lado do aspecto social, um aspecto individual, e a fala tem, ao lado do aspecto individual, um aspecto social.
}

Seria sem dúvida abusivo falar aqui de manualização, mas parece, entretanto, que a exposição dos saberes que deve ao mesmo tempo mostrar de qual(is) tradição(ôes) eles destacam, qual grau de inovação eles realizam, 
quais partilhas de conhecimentos eles estão implicando, é indissociável de um discurso forçado que as carrega e assegura sua transmissibilidade segundo as modalidades variadas.

Trata-se para nós tão somente de sugerir que não há, na ordem do que os didáticos chamam hoje os "saberes eruditos", de "conhecimentos puros" dissociáveis de um estilo expositivo consagrado à transmissão e repousando sobre uma representação global da disciplina.

No caso do estruturalismo e sua entrada no mundo escolar dos anos 1970 e nos manuais, pode-se dizer que esta representação foi cinco vezes ao menos marcada por:

- A) A identificação com a cientificidade ao preço, o mais frequente, de um certo "enrijecimento" das dicotomias saussurianas (sincronia, língua, forma, arbitrário, etc...);

- B) A homogeneidade de um campo intelectual, além da diversidade das escolas linguísticas, no esquecimento das tradiçóes que as viram nascer ${ }^{6}$. Desse ponto de vista, a obra de G. Lepschy, publicada em 1968 sob o título da Linguistica Estrutural, terá um papel importante na fixação e na difusão da imagem (de uma imagem) de um estruturalismo linguístico homogêneo;

- C) O reforço "dialético" da homogeneidade do estruturalismo por seu sucesso fora dos limites da linguística, e do fato das esperanças que ela fez nascer no campo das ciências do homem;

- D) A reivindicaçáo da autonomia da linguística fundada sobre a concepçáo da língua-sistema (com todos os equívocos presos aos deslizamentos de sentido do sistema à estrutura), autonomia que conduz mesmo L. Hjelmslev a promover a ideia de uma "Linguística especificamente linguística";

- E) A referência a um fundador, modulada, certo, em função de revisôes e refundaçóes incessantes, mas garante e dá caução a uma coerência disciplinar a qual fornecia as bordas da memória.

\section{Uma linguística da enunciaçáo?}

Voltando ao nosso propósito inicial: as teorias da enunciação e as

6 A filiação da glossemática com a tradição dinamarquesa da linguística, aquela do Círculo Linguístico de Praga com seus debates culturais da Europa central e da Rússia. Sobre este último ponto, cf. P. Sériot (1994). 
condiçôes "eruditas" de sua introdução nos "saberes ensinados". Está claro que o paradigma da enunciação - se existe - não responde às condiçôes de "pré-manualização" que foram aquelas do estruturalismo linguístico.

Se existe manuais universitários atestando a paradigmatização de teorias da enunciação materializada, eles são recentes e justificam sua própria existência náo em referência a uma memória - mesmo a curto prazo - nem a um projeto homogêneo, mas antes de tudo, ao contrário, por esmigalhamento do domínio, a impossibilidade de circunscrevê-lo de um único ponto de vista, e a necessidade de uma escolha epistemológica. Aqui, escolher entradas, já é tomar parte sobre o fundo. A dêixis, as modalidades, os atos de linguagem, a interação (J. Cervoni, 1987)...: estes itens engajam perspectivas sobre a extensão e os limites do campo. Se esta escolha é possível, outras também são. D. Maingueneau (1991): as pessoas e os dêiticos, os "tempos de indicativo", o discurso relatado. C. Kerbrat-Orecchioni (1980, 2a edição 97): a subjetividade na linguagem, a tipologia dos discursos, o sujeito tagarela... Resumindo:

os trabalhos, conduzidos sobre a enunciaçấo são de uma tal diversidade que
podemos nos perguntar o que pemite juntá-los sob uma apelação única...
o mais geral desses tratados é que eles repousam sobre uma concepção de
objeto da linguística mais extensiva que aquelas que tem servido de base, ao
longo dos séculos, às teorias que ressoaram mais ( J. CERVONI, 1987, p. 9).

Esta observação, que conduz significativamente seu autor a abordar as linguísticas da enunciação a partir das "linguísticas não enunciativas", tem o mérito de sublinhar o paradoxo que apresenta as teorias da enunciaçáo aos olhos do historiador. Como mostra S. Delesalle (1986) na Introdução aos Atos do Colóquio sobre "A história das teorias da enunciação", existe muitos elementos dispersos de teorização da enunciaçáo antes da época moderna (na virada dos séculos XIX e XX): na noção de prolatio, nos domínios de saber táo antigos quanto a retórica... mas seria em vão, entretanto, buscar se desprender, senão por ilusão retrospectiva, de uma tradição teórica na qual se enraizariam as teorias modernas. Ao inverso, com a modernidade, aparecem concepçôes múltiplas cujo ponto comum é sobretudo negativo: a recusa, ou a remodelação em profundidade da distinção língua/fala. O que permite à S. Delesalle sublinhar que "passou-se de uma concepção plural revestindo diferentes nomes a um nome único designando uma concepção sempre plural" (S. DELESALLE, 1986).

Mais amplamente, na virada dos dois séculos, os trabalhos 
abundam sobre as interaçóes, a linguagem interior, os atos de linguagem, a conversaçáa..., recolocando em causa a lenda dourada segundo a qual a autonomia da linguística não poderia ser conquistada senão a partir de um sacrifício (expiatório): aquele dos atos de linguagem concreta, do sujeito falante, que a lenda traz então o mais frequentemente ao indivíduo ${ }^{7}$. Sem dúvida, esses trabalhos evoluem aos limites das ciências da linguagem de sua época, entre psicologia, sociologia, psicosociologia, antropologia; mas mesmo se eles não chegam a se tornar "visíveis" como tais, sua permanência e sua relativa homogeneidade puderam todavia autorizar alguns pesquisadores a falar retrospectivamente de "tradição escondida". É o estruturalismo "generalizado" dos anos 1950 e 1960, e, de maneira mais perversa, a reação posterior aos formalismos de Praga, Copenhage e dos Estados Unidos, que farão esquecer o fundo dos debates sobre o qual se institui a célebre dicotomia saussuriana. Nesta medida, o lugar de emergência das linguísticas enunciativas deveria entấo ser buscadas menos em um antagonismo radical ou desenvolvimento do estruturalismo que no coração de sua gênese, de sua evolução, de suas contradiçôes.

De fato, por duas de suas referências cruciais ao menos, R. Jakobson e É. Benveniste, sabemos que o ponto de vista enunciativo emerge mais próximo do paradigma estruturalista tal como ele se (auto)instituiu, o qual nós arriscamos descrever alguns grandes traços característicos do ponto de vista disciplinar que é o nosso aqui.

Entretanto, podemos pensar que esta proximidade aparente dissimulou as questôes cujo ponto de vista da enunciação era portador: do sujeito falante, do qual parece bem difícil dizer que está totalmente ausente da preocupação dos linguistas estruturalistas e dos debates a partir dos quais eles se constituíram em uma continuidade problemática com Saussure, ao "sujeito da enunciaçáa" tal como Benveniste o distingue do sujeito do enunciado, náo é certo que os dois linguistas, apesar dos recortes evidentes, realizam o mesmo percurso. Esta divergência na proximidade dos pontos de partida, constata-se, por sua vez, nas trocas entre os dois linguistas no que concerne à tomada da perspectiva dos fatos da enunciação, e a reencontramos,

7 Sobre esta dupla operação de reduçấo do sistema saussuriano à estrutura, do sujeito falante ao indivíduo, perpetuada por aqueles mesmos que se dáo por tarefa "reabilitar" o sujeito contra a estrutura, cf. os trabalhos de H. Meschonnic. Entre eles, em particular, Meschonnic (1995).

8 B. Nerlich (1986) oferece a este propósito um quadro muito convincente da virada do século, mesmo se podemos emitir reservas sobre a pertinência historiográfica da noção de "tradição escondida". 
igualmente, nas representaçóes disciplinares que eles constroem.

É a Benveniste (1956; "La nature des pronoms", in For Roman Jakobson, Mouton, La Haye, PLG chap. XX), por exemplo, que nos remete Jakobson em 1957 (Shifters, verbal categories, and the Russian verb", retomado em Jakobson, 1963), a propósito do pronome de primeira pessoa e de seu funcionamento semântico como "index". Mas esta referência é principalmente colocada a serviço de um comentário do famoso esquema da comunicação, que ela complica, colocada à prova e, finalmente, confirmada. Nesta medida, os embrayeurs introduzem para Jakobson uma espécie de hierarquia nas funçôes da linguagem: do mesmo modo que os nomes próprios apresentam a particularidade de remeter o código ao código, os embrayeurs apresentam aquele de remeter a mensagem à mensagem, nomes próprios e embrayeurs figuram entáo como funçóes de segundo grau na comunicação ao lado das funçóes de primeiro grau (expressividade, conatividade, referência). É então essencialmente às noçôes de função e de comunicação que se interessa Jakobson no que concerne à indexicalidade dos pronomes. A análise de sua particularidade semântica está integrada a uma abordagem, lembramos, que visa antes de tudo a uma taxionomia exaustiva e universal de todas as "categorias verbais genéricas". Nesta medida, o empréstimo à Benveniste parece bem seletivo, pois ele exclui o que podemos considerar como o feixe dos fatos de enunciação, que Benveniste não vai parar, pelo contrário, de retrabalhar e sistematizar até sua exposição em 1970 ("O aparelho formal da enunciação", PLG 2, cap. 6): nem o estatuto do "ele" "não-pessoa", nem aquele da dêixis, nem a distinção dos planos de enunciação (história/discurso) concernente, entretanto, a distribuição das formas verbais não são evocadas. Para simplificar, poderse-ia dizer que é toda a dimensão do "discurso" próprio à Benveniste, a dimensão da significância ligada ao plano de análise semântica distinta do plano semiótico que se encontram assim contornados. De fato, os embrayeurs - mas ele não retoma nada dessa denominação metafórica são menos, para Benveniste, signos que propriedades fundamentais, que os traços de uma atividade linguística irredutível à noção de signo, tanto ela é verdadeira que se trata, segundo a célebre formulaçáo "de ultrapassar a noção saussuriana do signo como princípio único, o qual dependeriam, ao mesmo tempo, da estrutura e do funcionamento da língua" (PLG 2, p. 66).

Trata-se entáo menos, para Benveniste, de dar conta do funcionamento de um código e do traço de um sujeito que lhe pré-existiria que de colocar em evidência os processos de subjetivação, o "campo posicional do sujeito" (PLG 1, p.174). Lembramos, com efeito, das formulaçóes fortes do autor 
dos Problemas a esse propósito:

\begin{abstract}
A 'subjetividade' a qual nós traçamos aqui é a capacidade do locutor se colocar como 'sujeito'. Ela se define, não pelo sentimento que cada um sente de ser ele mesmo [...] mas como a unidade psíquica que transcende a totalidade das experiências vividas que ela reúne e que assegura a permanência da consciência (PLG 1, p. 259-260).
\end{abstract}

Ali onde Jakobson vê a necessidade de retrabalhar a distinção da língua/ fala a fim de redistribuir de outro modo o par social/individual (cf. citação supracitada) e de integrar um ponto de vista enunciativo deixando intacto o quadro semiótico (no sentido de Benveniste) de análise funcionalista e comunicacional de Saussure (lido por Jakobson), é sobretudo a uma refundação que aspira Benveniste. A homonímia do termo comunicação empregada pelos dois linguistas não deve enganar. A concepção da dupla significância implica que das unidades mínimas à totalidade - a frase para Benveniste - sejamos obrigados de mudar radicalmente de perspectiva: "Com a frase deixamos o domínio da língua como sistema de signos, e entre um e outro universo, aquele da língua como instrumento de comunicação, cuja expressão é o discurso" (PLG 1, p. 129-130).

Nesta medida, o estatuto da linguística do discurso que Benveniste chama por sua vontade não tomaria lugar em uma representação disciplinar onde a linguística teria unicamente que pensar suas articulaçóes com os domínios conexos por uma abordagem integrativa do tipo daquele de Jakobson. A dimensão enunciativa e o estatuto conferido a ele parecem juntos destacar em Benveniste seja um déficit de fundação a satisfazer, seja de uma extensão a realizar, enfim, de uma problemática (talvez $o$ problema de linguística geral) que não pode se abrir senão no desconforto de uma exploração sujeita a retornos incessantes e como um interior oco.

É que, se o mundo fechado da dimensão semiótica se opóe ao universo aberto do discurso, semântica e semiótica concernem a uma mesma realidade, a língua: é esta dificuldade que os leitores críticos de Benveniste atribuem seja à confusão (A. Culioli, 1983), seja à contradição (I. Tamba-Mecz, 1983), seja a uma fidelidade a Saussure para ultrapassálo (C. Normand, 1989), seja enfim às relaçóes de integração recíproca da semântica e da semiótica, a língua constituindo uma espécie de fita de Moebius (S. de Vogüe, 1997). São os "signos vazios" da língua que instancia o sujeito da enunciação em "apropriando-se", por exemplo, mas no mesmo movimento, nenhuma instanciação seria possível sem a estruturação que 
autorizam sozinhos os signos. Como escreve S. de Vogüe (1997, op. cit., p. 156), a língua de Benveniste "em cada um de seus pontos se volta para integrar o seu exterior.

\section{Enunciaçáo e didatização}

Esta última hipótese, que não exclui a precedente, apresenta a vantagem para o nosso ponto de vista - disciplinar - de pontuar a dificuldade principal concernente a uma visibilidade/difusão/transmissão das teorias da enunciação e, também, sua assimilação no corpo de saberes ensinados: relatadas a uma de sua fonte principal e a mais exigente, Benveniste, elas desenham uma configuração dificilmente assinalável na medida em que em que a língua é concernida aos limites da linguística, do semiológico e do pragmático no que ela tem, pois, ao mesmo tempo de irredutível e aberta a um fora proliferando e pouco estável (as interaçôes, rituais sociais, as operaçôes mentais...). Como foi mostrado (por S. de Vogüe, op. cit.), Benveniste joga sem dúvida toda a ambivalência que se detém no termo "integração": ao mesmo tempo, englobamento e inserção, para "abrir" a língua ao domínio do discurso, mas sem jamais sacrificar a língua a seu "fora". Deste ponto de vista, o texto célebre dos PLG (2, p. 62) onde Benveniste descreve as relaçóes da língua e da sociedade, encontrando por aí, talvez, o sentido profundo da fórmula saussuriana segundo a qual "o caráter social da língua é um de seus caracteres interno", possui um valor emblemático, ao mesmo tempo em que constitui talvez o último avatar da maneira pela qual os linguistas utilizam desde o fim do século XIX as dicotomias constitutivas da linguística.

\footnotetext{
Se nós nos interrogamos sobre a situação respectiva da língua e da sociedade [...], o sociólogo observará que a língua funciona no interior da sociedade que a engloba [...] mas a consideraçáo semiológica inverte essa relação, porque somente a língua permite a sociedade [...] poderíamos dizer entáo que é a língua que contem a sociedade. Assim, a relaçáo de interpretância, que é semiológica, vai ao inverso da relação de encaixe, que é sociológica.
}

É porque se procuraria em vão em Benveniste a representação totalizante - e bem tranquilizante - de saberes do signo que encontramos muitas retomadas em Jakobson, especialmente nas relaçóes redigidas para a UNESCO sobre "as relaçôes entre as ciências da linguagem e as outras ciências". A noção de "comunicação" - aí ainda - permite repartir o conjunto 
das ciências humanas sobre três círculos concêntricos:

\begin{abstract}
Strês ciências pertencem a um conjunto, englobando uma a outra e representam três graus de generalização crescente: 1) o estudo da comunicação de mensagens verbais ou linguística, 2) o estudo da comunicaçáo de mensagens quaisquer, ou semiótica (compreendido aí a comunicaçẫo de mensagens verbais), 3) o estudo da comunicaçáo ou antropologia social e econômica (compreendido aí a comunicação de mensagens) (1970, p. $9-113)$.
\end{abstract}

"Integrar", para Jakobson aqui, é situar os saberes da língua no encerramento (enciclopédico) de um círculo, na hierarquia acumulativa do encaixe, na ordem dos conhecimentos que procede por generalizaçôes sucessivas e crescentes. Em Benveniste, ao contrário, a relação da linguística às outras disciplinas parece reproduzir a estrutura em quiasma alojada no coração da análise da língua da qual nós falávamos anteriormente.

$\mathrm{O}$ estatuto da linguística é frequentemente referido a um futuro indeterminado, um horizonte ideal e projetivo cujos nomes são menos critérios de classificação que projetos que dão sentido a seus desenvolvimentos atuais: semiologia, semiologia de segunda geração, semântica, discurso...

A integração no círculo enciclopédico dos conhecimentos tem então menos importância que a perspectiva de fundação: qual destino para a significação, não somente na linguística, mas nas outras disciplinas da cultura?

A descontinuidade dos pontos de vista, enfim, toma o passo sobre a generalizaçấo progressiva. Quando se trata da língua: do signo ao sintagma, do sintagma à palavra e à frase, Benveniste insiste sobre mudanças de perspectiva e sobre as integraçóes paradoxais de perspectivas. Do mesmo modo, nas relaçóes da linguística com outras ciências da cultura, nenhuma articulação parece poder se produzir sem pressuposição mútua (cf. supra para as relaçôes da linguística e da sociologia).

Considerando a enunciação nas teorias linguísticas, temos um desenho dos perfis disciplinares pouco homogêneos, mesmo quando eles são fortemente semelhantes. Para resumir, após esse longo desenvolvimento: do paradigma comunicacional gerador de uma representação enciclopédica das ciências do signo, ao paradigma da semantização que lembra uma refundação das ciências da linguagem em torno da língua e dos discursos, ao mesmo tempo uma dupla polaridade ofertada pelos "saberes eruditos" e "as 
escolhas" didáticas a operar. Há também a proximidade ao estruturalismo e uma representação dos saberes onde a temática da enunciação aparece ora como um complemento, ora como uma alternativa aos linguísticos das estruturas (elas mesmas pouco homogêneas), quando não aquelas da língua. Há enfim o peso respectivo de duas histórias, de duas temporalidades, aquelas da história das ideias linguísticas e aquela das tradiçôes escolares, histórias e temporalidades que presidem a contextualizaçóes diferentes.

Para o que concerne ao ensino de francês, parece claro que a "conjuntura" geral da escola favoreça - mas com quais ambiguidades? - a introdução do ponto de vista enunciativo nos manuais e nas práticas de ensino. Podemos aqui enumerar alguns parâmetros, explicitamente ou implicitamente levantados nos programas dos ciclos do colégio e seus comentários:

- A passagem da era da "linguística aplicada", contemporânea da dominaçáo das representaçóes disciplinares ligadas ao estruturalismo, à "era da didática", contemporânea, ela, da emergência do campo enunciativo;

- A preocupação da finalização dos saberes e o recentramento das aprendizagens em torno das competências fundamentais (ler/ escrever/comunicar);

- A redescoberta do continente retórico, e a certeza que, Perleman e Ducrot cooperam, é de uma "nova" retórica que está em questão;

- A organização das aprendizagens em torno da tipologia dos textos e de sua coerência;

- O imperativo de descompartimentação, que recentra as atividades da sala de aula sobre as finalidades, mais do que sobre rotinas e a tradição das matérias e "rituais" escolares;

- A consciência cada vez mais clara que se desempenha no ensino de francês uma parte presa entre o progresso das performances dos alunos e o acesso à análise metalinguística (o que não quer dizer uma alternativa).

Mas resta talvez o essencial, que sublinham as nova Instruçóes Oficiais do colégio e seu comentário: o imperativo do sentido. Os alunos que não são aprovados na escola faltariam literalmente o sentido, eles não saberiam se orientar, porque eles não saberiam quem são ou onde estáo, nem a quem eles se dirigem, resumindo, porque eles náo se adaptam ao dispositivo que lhe é destinado. Entretanto, tudo mostra que a escola hoje demanda e não 
somente é receptora de todo o dispositivo teórico permitindo compreender porquê a obrigaçáo escolar é recusada por aqueles a quem ela é ofertada e suposta aproveitar mais. Deste ponto de vista, o investimento no qual noção de "discurso" é objeto na organizaçáo de ensino do francês no colégio, a apagamento correlativo do imperativo de domínio e sobretudo de conhecimento da língua (seu assujeitamento ao domínio dos discursos) e o lugar de todas as ambiguidades: ele excede largamente a concentração frágil, problemática, mal estabilizada das categorias linguísticas homonímias ofertadas pelos "saberes eruditos", ele arrisca "esclarecer", as finalidades do ensino do francês por uma decisão institucional que decide em favor das práticas linguageiras em detrimento do conhecimento dos funcionamentos linguísticos, lá onde sua articulação que é necessário realizar sem pré-julgar uma harmonia pré-estabelecida. Tem todas as chances, enfim, de reconduzir os mal-entendidos inumeráveis que se prendem, em geral e nos saberes linguísticos, a noção de "comunicação", creditando ao mesmo tempo às teorias da enunciação um poder exorbitante: aquele de fornecer aos sujeitos falantes a representaçáo de seu estatuto de sujeitos-cidadãos.

Enfim, a manualização dos saberes concernentes à enunciação aparece no cruzamento das maiores séries de restrições, de contextualizaçóes, e de histórias: representação de saberes em disciplina no interior mesmo dos saberes eruditos, integração em um complexo de conhecimentos, de práticas e de finalidades na escola sob o nome de "francês". A hipótese que nós arriscamos aqui é que entre essas duas séries há um continuum de representaçôes, mesmo heterogênea ou deslocadas, mais do que ruptura. A manualização dos saberes linguísticos não é certamente redutível a uma degradação, uma perda de substância de conhecimentos vivos, mas representa, sem dúvida, um resultado de um processo contínuo que, da invenção ao re-investimento nos saber-fazer escolares, atravessa muitos tipos de restriçôes ligadas à transmissão. Não ganhamos, pois, em rigidificar em oposição a distinção "saberes eruditos"/"saberes ensinados": o imperativo da transmissão é o eixo sobre o qual as práticas normatizadas da invençáo e aquelas do ensino comunicam entre elas.

\section{Referências}

AUROUX, S. La catégorie du "parler" à la fin du XIXe siècle. Romantisme. Paris: SEDES, 1979. 
La notion de linguistique générale. Histoire, Épistémologie, Langage, t. 10, Fasc. 2, A. Meillet et la linguistique de son temps, Paris: PUV, 1988.

BENVENISTE, É. Problèmes de linguistique générale 1 et 2, Paris: Gallimard (coll. Tel), 1966-1970.

BOUQUET, S. Introduction à la lecture de Saussure. Paris: Payot, 1997.

CERVONI, J. L'énonciation, Paris: PUF (coll. Linguistique nouvelle), 1987.

CHISS, J.-L.; PUECH, C. Énonciation, interaction, conversation: les théories du langage entre le psychique et le social. Histoire, Épistémologie, Langage, t. 11, fasc. 2, Paris: PUV, 1989.

Saussure et la constitution d'un domaine de mémoire pour la linguistique moderne. Langages, n. 114, Paris, Larousse, 1994.

. La linguistique structurale, du discours de fondation à

l'émergence disciplinaire. Langages, n. 120, Paris: Larousse, 1995.

. Fondations de la linguistique. 2. éd. Bruxelles: Duculot, 1997.

CULIOLI, A. Théorie du langage et théorie des langues. Émile Benveniste aujourd'hui, Bibliothèque de l'Information Grammaticale, 1983.

DELESALLE, S. «Introduction » à " L'histoire des théories de l'énonciation ». Histoire, Épistémologie, langage, t. 8, fasc. 2, Paris: PUV, 1986.

ENGLER, R. (éd.). Cours de Linguistique Générale de F. de Saussure, édition critique. O. Harrassowitz, Wiesbaden. 1968 et 1974. 
GODEL, R. Les sources manuscrites du Cours de Linguistique Générale, Genève-Paris: Droz, 1957.

HALTÉ, J.-F. Didactique et enseignement du français. Perspectives didactiques en français, actes du colloque de Cerisy. Centre d'Analyse Syntaxique de l'université de Metz, Metz, 1990.

HUOT, H. Enseignement du français et linguistique, A. Colin, Paris. 1981

JAKOBSON, R. Essais de linguistique générale 1 et 2, Paris : Les éditions de Minuit, 1963-1970

KERBRAT-ORECCHIONI, C. L'énonciation. Paris: Armand Colin, 1980, 1997 2e éd.

LEPSCHY, J. La linguistique structural. Paris: Payot, 1968.

MAINGUENEAU, D. L'énonciation en linguistique française. Paris: Hachette Supérieur, 1991.

MESCHONNIC, H. Seul comme Benveniste ou comment la critique manque de style. Langages, n. 118, Larousse, Paris, p. 31-55, 1995.

NERLICH, B. La pragmatique: tradition ou révolution dans la linguistique française. Frankfurt: Peter Lang, 1986.

NORMAND, C. (éd.). Le sujet entre langue et parole. Langages, n. 77, Didier-Larousse, Paris, 1985.

. (éd.) Histoire, Épistémologie, Langage, t. 11, fasc. 2, Constitution de la sémiologie chez Benveniste, PUV, 1989.

PAVEL, T. Le mirage linguistique. Paris : Éditions de Minuit, 1988. 
PETITJEAN, A. Pour une didactique de la littérature. In: Halté, J.-F., op. cit., p.101-128, 1990.

RASTIER, F. Le problème du style pour la sémantique du texte. In: Molinié et Cahné. Qu'est-ce que le style?, Paris: PUF, 1994.

SCHLANGER, J. L'invention intellectuelle. Paris: Fayard, 1983.

. La mémoire des oeuvres. Paris: Nathan, 1992 a.

. Fondation, nouveauté, limite, mémoire. Communications, n. 54, Seuil, Paris, p. 289-298, 1992b.

SEGRE, C. Apogée et éclipse de la stylistique. Cahiers Ferdinand de Saussure, n. 46, Droz, Genève, 1992.

SÉRIOT, P. L'École de Prague : l'apport épistémologique. Cahiers de l'ISL, Université de Lausanne, Lausanne, 1994.

TAMBA-MECZ, I. À propos de la distinction entre sémiotique et sémantique. Émile Benveniste aujourd'hui. Bibliothèque de L'Information grammaticale, 1983 .

VOGÜÉ DE, S. La croisée des chemins. Remarques sur la topologie des relations langue/discours chez Benveniste. LINX, $\mathrm{n}^{\circ}$ spécial, Benveniste vingt ans après, Université de Paris X/Nanterre, 1997.

DOI - http://dx.doi.org/10.5902/2179219436594 